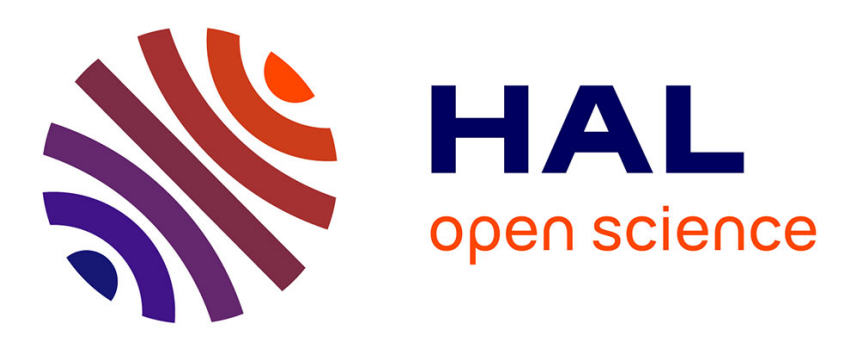

\title{
Effects of juvenile hormone analog on physiological and behavioral maturation in honeybee drones
}

\author{
Ken-Ichi Harano
}

\section{To cite this version:}

Ken-Ichi Harano. Effects of juvenile hormone analog on physiological and behavioral maturation in honeybee drones. Apidologie, 2013, 44 (5), pp.586-599. 10.1007/s13592-013-0208-7 . hal-01201328

\section{HAL Id: hal-01201328 \\ https://hal.science/hal-01201328}

Submitted on 17 Sep 2015

HAL is a multi-disciplinary open access archive for the deposit and dissemination of scientific research documents, whether they are published or not. The documents may come from teaching and research institutions in France or abroad, or from public or private research centers.
L'archive ouverte pluridisciplinaire HAL, est destinée au dépôt et à la diffusion de documents scientifiques de niveau recherche, publiés ou non, émanant des établissements d'enseignement et de recherche français ou étrangers, des laboratoires publics ou privés. 


\title{
Effects of juvenile hormone analog on physiological and behavioral maturation in honeybee drones
}

\author{
Ken-ichi Harano \\ Honeybee Science Research Center, Tamagawa University, Machida, Tokyo 194-8610, Japan
}

Received 31 January 2013 - Revised 26 March 2013 - Accepted 3 April 2013

\begin{abstract}
The functions of juvenile hormone in the physiological and behavioral maturation in Apis mellifera males (drones) were investigated by application of a juvenile hormone analog, methoprene. No evidence was found for the stimulation of maturation of male reproductive organs by methoprene. The dry weight of the seminal vesicle and reproductive accessory gland was slightly but significantly lighter in drones treated with a high dose $(100$ or $500 \mu \mathrm{g} / \mathrm{male})$ of methoprene than drones treated either with a low dose $(1 \mathrm{or} 10 \mu \mathrm{g} / \mathrm{male})$ or solvent control only. Methoprene accelerated in-colony male movement from the center to the periphery. It also induced earlier diet transition from pollen and jelly-like materials to honey. These results suggest that juvenile hormone acts as a behavioral pacemaker rather than as a gonadotropin in drones.
\end{abstract}

behavioral development / drone / juvenile hormone / reproduction / sexual maturation

\section{INTRODUCTION}

The reproductive division of labor characterizes eusocial insects. In these insect colonies, some individuals monopolize reproduction, while others perform various colony maintenance activities. In honeybees, the colony consists of a single egg-laying queen and up to several tens of thousands of sterile female workers engaged in colony maintenance. Like the queen, a few hundred drones (males) also engage exclusively in reproduction without colony maintenance activities. Since these differences between colony members are the basis of eusocial insect societies, research has focused on the physiological mechanisms underlying the reproductive division of labor (reviewed in

Corresponding author: K. Harano, kharano@lab.tamagawa.ac.jp Manuscript editor: Klaus Hartfelder
Robinson and Vargo 1997; Hartfelder 2000; Harano and Sasaki 2013).

Juvenile hormone $(\mathrm{JH})$ released from the corpora allata plays a key role in reproduction in many insects (Wyatt and Davey 1996), where it regulates oogenesis, vitellogenin synthesis, ovary development, mating behavior, etc. Stimulating ovaries to produce mature eggs is the most universal function of this hormone in adult insects, and this gonadotropic function has been reported in some eusocial Hymenoptera, including paper wasps (Bohm 1972; Röseler et al. 1980), bumblebees (Bloch et al. 1996, 2000), and the fire ant (Kearney et al. 1977; Barker 1978; Vargo and Laurel 1994). However, this is not the case in honeybees where changes in $\mathrm{JH}$ synthesis and hemolymph titer are not correlated with ovarian status (Robinson et al. 1992; Fahrbach et al. 1995), and neither allatectomy (Laere 1974; Engels and Ramamurty 1976) nor $\mathrm{JH}$ and $\mathrm{JH}$ analog (JHA) treatment (Engels 1978; Robinson et al. 1992) exerted a substan- 
tial effect on egg production and oviposition in queens and workers in the European honeybee, Apis mellifera L.

In contrast to the abundant information about the gonadotropic functions of $\mathrm{JH}$ in female insects, the role of $\mathrm{JH}$ in the maturation of reproductive organs in males is not well understood. Spermatogenesis proceeds in the testis before or after adult emergence, and $\mathrm{JH}$ does not appear to regulate this process (Wyatt and Davey 1996). On the other hand, previous studies show that $\mathrm{JH}$ promotes the secretory activity of reproductive accessory glands in males of various insects such as Rhodnius (Wigglesworth 1936), cockroaches (Blaine and Dixon 1973; Piulachs et al. 1992), locusts (Loher 1961), mosquitoes (Ramalingam and Craig 1977), and butterflies (Herman 1975; Herman and Bennett 1975).

In honeybee males, spermatozoa produced in the testes during the pupal period are transferred to seminal vesicles in the early adult period where they are stored until mating (Snodgrass 1956; Jaycox 1961). The reproductive accessory gland is filled with mucus and thickens during the week after emergence. The mucus is ejaculated with semen into the queen's genital tract at mating. Colonello and Hartfelder (2003) showed that the amount of protein in the secretion of the accessory gland increases and its protein profile becomes simpler with aging, reporting that injection with 20-hydroxyecdysone delayed such changes. They argued that the maturation of this organ may be controlled by coordination of ecdysteroids and $\mathrm{JH}$ actions, but the effect of $\mathrm{JH}$ has yet to be proven in honeybee males.

In honeybee workers, JH has gained a new function instead of a gonadotropic role. Workers perform various colony maintenance tasks, such as cell cleaning, comb building, brood nursing, and foraging, basically based on age (Winston 1987). The tasks are associated with worker location in the colony (Seeley 1982). For example, young workers tend to stay in the colony center and perform nursing. As the workers age, they move out to the peripheral area and perform other tasks, such as constructing comb, storing food, and guarding the colony entrance. Finally, they leave the colony for foraging. This age-related polyethism is regulated by $\mathrm{JH}$. The hemolymph $\mathrm{JH}$ titer increases with age and differs with task (Robinson et al. 1991; Jassim et al. 2000). The application of JH or a JHA, such as methoprene, accelerates the behavioral transition and causes early onset of foraging (Jaycox et al. 1974; Jaycox 1976; Robinson 1985, 1987; Sasagawa et al. 1989). Since these treatments do not trigger a particular behavior, but accelerate the schedule of a behavioral transition, $\mathrm{JH}$ is thought to act as a behavioral pacemaker in honeybee workers (Robinson and Vergo 1997).

Drones show similar behavioral development to workers in the sense that they remain in the colony for several days after emergence before making the first flight at 5-8 days old (Ruttner 1966; Rueppell et al. 2006). The first few flights are brief orientation flights; longer mating flights are made later when they are sexually mature (Ruttner 1966; Winston 1987). Drones die soon after successful copulation with a queen on their mating flight. Drones that fail to mate successfully return to the colony and make mating flights on later days. The JH synthesis rate and hemolymph titer show a monomodal pattern with a peak at the onset of flight (Tozetto et al. 1995; Giray and Robinson 1996). In addition, topical application of JH or methoprene in newly emerged drones accelerates the onset of flight (Giray and Robinson 1996; Tozetto et al. 1997). These findings suggest that $\mathrm{JH}$ regulates behavioral development in drones.

Recently, Harano et al. (2008) demonstrated that $\mathrm{JH}$ raises the brain dopamine level during the early adult life of drones. Dopamine increase is thought to activate the motor system of drones for flight (Akasaka et al. 2010; Mezawa et al. 2013), but may have other functions because biogenic amines including dopamine are known as pleiotropic molecules (Evans 1980; Sasaki and Harano 2010). The increase in brain dopamine as well as $\mathrm{JH}$ hemolymph titer matches the maturation of reproductive organs in drones (Harano et al. 2008). Moreover, a gonadotropic function of dopamine is observed in queenless workers with 
developing ovaries (Harris and Woodring 1995; Sasaki and Nagao 2001; Dombroski et al. 2003). It is possible that JH regulates both behavioral and physiological maturation through a dopaminergic system in males, unlike in females.

In this study, we applied various amounts of the JHA, methoprene to drones and weighed the testis, seminal vesicle, and accessory gland to examine the gonadotropic function. To clarify the effects of $\mathrm{JH}$ on non-flight behaviors in drones, two age-related behaviors were investigated. Free (1957) and Ohtani and Fukuda (1977) observed that young drones were frequently found in the center of the colony, with older drones at the periphery. Free (1957) also found that young drones were more frequently fed by workers than old drones. Consequently, we examined male food consumption and distribution in the colony.

\section{MATERIALS AND METHODS}

\subsection{Outline of experiments}

Three experiments were conducted to reveal the functions of $\mathrm{JH}$ in the sexual development of drones. In experiment 1 , the effect of methoprene on the maturation of male reproductive organs was examined. Drones were topically applied with $1-500 \mu \mathrm{g}$ of methoprene or solvent alone at emergence ( 0 day) and their reproductive organs were weighed every 2 or 3 days after the application ( $N=9-34$ for each age). To examine the effect of JHA at different developmental stages, 33-40 drones treated on day 2 or 5 were dissected 3 or 4 days after the application for measurement of reproductive organs.

In experiment 2 , the effect of JHA on in-colony male movement was evaluated. Fifty-four to fifty-seven drones were treated with 1 or $100 \mu \mathrm{g}$ of methoprene or solvent only at emergence and their position within the hive was recorded for seven consecutive days from day 2.

In experiment 3 , the effect of JHA treatment on diet transition was investigated. Nineteen to thirty-seven drones were treated with 10 or $100 \mu \mathrm{g}$ of methoprene or solvent only at emergence and their mid-gut content was compared on days 2,5 , and 8 .

\subsection{Bees}

Colonies of the European honeybee A. mellifera L. reared in Tamagawa University were used for experiments. They are a crossbreed derived mainly from Italian bees. We used one- or two-storied hives with 9-18 frames for those colonies; each frame was populated by about 2,000 workers during the experiments. To obtain many newly emerged drones simultaneously, we provisioned frames in the experimental colonies with drone comb wax foundation (Kumagaya Yoho Co., Saitama, Japan). Frames with developing drone pupae were removed from the hives 2-3 days before expected emergence and placed in an incubator at $34{ }^{\circ} \mathrm{C}$. Newly emerged drones $(<24 \mathrm{~h})$ were paint-coded (Paint Marker, Mitsubishi Co. Ltd., Tokyo, Japan) on the thorax and/or abdomen to identify age after emergence. They were returned to the parent colony after marking.

\subsection{JHA treatment}

Methoprene (Sigma-Aldrich, St. Louis, MO) was diluted in 2-propanol (Wako, Osaka, Japan) at concentrations of $1-500 \mu \mathrm{g}$ per $2 \mu \mathrm{L}$ of 2-propanol and $2 \mu \mathrm{L}$ of the methoprene solution was applied topically to the dorsal surface of the abdomen using a $50-\mu \mathrm{L}$ microsyringe (Hamilton, Reno, NV). The range of dose was chosen based on Harano et al. (2008), who showed that $100 \mu \mathrm{g}$ of methoprene sufficiently induced an increase of brain dopamine in drones. As a control, $2 \mu \mathrm{L}$ of 2-propanol was applied alone in the same manner. Unless otherwise stated, the methoprene solution was applied to newly emerged drones (day 0 ) before return to the parent colony.

\subsection{Experiment 1: dissection and measurement of reproductive organs}

To determine the effect of methoprene on the maturation of reproductive organs, treated and control drones were sampled for dissection on days $0,2,5,8$, 11, and 14. All drones were dissected within 1 day of sampling because cooling or freezing often causes ejaculation or damages the organs. Pairs of testes, seminal vesicles, and accessory glands were carefully removed using dissection scissors and tweezers and 
placed on glass slides. Any damaged organs or with discharged contents were discarded. The organs were dried at $100{ }^{\circ} \mathrm{C}$ for $2 \mathrm{~h}$ in an oven (DKN 601, Yamato Scientific Co. Ltd., Tokyo, Japan). The dried organs were scraped from the glass slide with a razor and weighed to the nearest $0.1 \mathrm{mg}$ using a digital balance (AUW220, Shimadzu, Kyoto, Japan). This experiment was repeated three times with different colonies and different doses of methoprene (trial $1,100 \mu \mathrm{g} /$ drone; trial 2,10 and $500 \mu \mathrm{g} /$ drone; trial 3, 10 and $100 \mu \mathrm{g} /$ drone).

In other experiments, $100 \mu \mathrm{g}$ of methoprene diluted in $2 \mu \mathrm{L}$ of 2-propanol was applied to drones on day 2 or 5 to examine the effects of methoprene on individuals with developing reproductive organs. Control drones were treated with $2 \mu \mathrm{L}$ of 2-propanol alone on the same days as the methoprene treatments. Drones treated on days 2 and 5 were sampled for dissection on days 5 and 9 , respectively. To avoid loss of drones caused by flying, they were held above the queen excluder in the upper part of the twostoried hive. We have preliminary unpublished data confirming that this confinement has no effect on the maturation of male reproductive organs (S. Hayashi, M. Sasaki and K. Harano, unpublished data). In other experiments, drones were free in the hive.

\subsection{Experiment 2: observation of the distribution of drones in colony}

To examine whether JH regulates in-colony movement of drones (Free 1957; Ohtani and Fukuda 1977), we recorded the distribution of methoprene-treated and control drones in the colonies. Newly emerged drones were methoprene-treated as described above and returned to a colony with nine frames in a one-storied hive. About 1 week before the drones were returned to the colony, the colony frames were arranged with two honey-filled frames, in which nearly all cells were filled with honey and about half were sealed, on either side of five frames, each with a large central brood area and some surrounding honey. There were pollen stores between the brood and honey on the central five brood frames, but few pollen stores on the two outside frames on each side. The numbers of drones on the four honey frames and five brood frames were counted in the morning (0900-1100 hours) on days $2-8$ after drone introduction.

\subsection{Experiment 3: examination of mid-gut contents}

The effect of $\mathrm{JH}$ on feeding was examined by inspecting mid-gut contents in treated and control drones. Drones on days 2, 5, and 8 were sampled randomly with respect to position in the colony. They were immediately put in a small plastic bag $(15 \times$ $20 \mathrm{~cm}$ ) and cooled in ice to minimize the impact of ongoing digestion.

The mid-gut is filled with yellowish or colorless translucent liquid with some yellow or cream-colored materials as a clump at the rectum side. All nonliquid materials were treated as "solid" in this present study. The mid-gut was removed by dissection and classified into three grades depending on the amount of contained solid materials: grade I-more than one third of mid-gut filled with solid materials; grade II-less than one third of mid-gut filled with solids; grade III — no solids visible in mid-gut. The experiment was repeated twice with different colonies at different doses (trial $1-10 \mu \mathrm{g} /$ drone; trail 2-10 and $100 \mu \mathrm{g} / \mathrm{drone})$. Trials used colonies on five brood frames with four honey-filled outer frames, as described in Section 2.4. Some day 2 drones were sampled from the central brood frames and peripheral honey-filled frames to examine the effects of location in the colony on mid-gut content.

\subsection{Statistics}

The effect of methoprene as well as that of age on the maturation of reproductive organs was tested using two-way ANOVA. When a significant effect of treatment was detected by this method, the data were compared between the experimental groups for each age class using one-way ANOVA with Tukey's multiple comparison. To examine the effect of methoprene on distribution in the colony, the proportions of drones on the peripheral honey-filled frames were compared between drone groups using the chi-square test; when a significant difference was detected by the test, Tukey's wholly significant difference (WSD) test was performed as a post hoc multiple comparison test. The effects of methoprene on mid-gut contents were evaluated by comparing the distributions of grades I-III using the Mann-Whitney $U$ test or the Kruskal-Wallis test followed by the 
Steel-Dwass test between the treated and control drones. All statistical tests were performed at the $5 \%$ significance level. An Excel add-in software, Ekuseru-Tokei 2007 (SSRI, Tokyo, Japan), was used to perform the above statistical tests, excluding Tukey's WSD test, which was calculated manually.

\section{RESULTS}

\subsection{Experiment 1: maturation of reproductive organs}

In the measured dry weights of testis, seminal vesicle, and accessory gland on days 0-14, control drones showed a similar pattern of maturation with age in all three trials. The testes shrank and lost weight rapidly until day 8 . Seminal vesicles and accessory glands gained weight, and the change was almost completed by day 5 (Figure 1).

The effects of methoprene on the weight of reproductive organs were tested first for all data including all age classes using two-way ANOVA (Table I). The testis was unaffected by the methoprene treatments in terms of dry weight.

Two-way ANOVA detected a significant difference for seminal vesicles in two of three trials (Table I), where a high methoprene dose $(100$ or $500 \mu \mathrm{g})$ resulted in lighter seminal vesicles, but a significant difference between the treated and control drones was only detected on days 5 and 8 (Tukey's multiple comparison: $P<$ 0.05 ; Figure 1). On day 14 of trial 2 (Figure 1f), a significant difference was found among three drone groups with one-way ANOVA, but not between controls and any treated drones using post hoc multiple comparison $(P>0.05)$. When the dry weights of seminal vesicles were averaged for days $5-14$, the mean was reduced by $8-9 \%$ in drones treated with a high methoprene dose compared to the respective controls in trials 1 and 2.

Methoprene treatments had a clearer effect on the weight of the accessory gland. All repetitions showed a reduction in the dry weight of the accessory gland compared to controls when drones were treated with 100 or $500 \mu \mathrm{g}$ of methoprene (Table I and Figure 1). Significant differences between the treated and control drones were found for all ages after day 2 (Tukey's multiple comparison: $P<0.05$ ), except for day 14 in trial 2 . With respect to the averaged dry weight for days 5-14 (trials 1 and 3) or days 5-11 (trial 2), the weight of the accessory gland decreased by $7-14 \%$ in treated drones compared to the controls. The effect of a low-dose treatment by applying $1 \mu \mathrm{g}$ of methoprene to newly emerged drones was also investigated in the same way as the higher doses. The dry weights of the three reproductive organs were measured on days 2 and 8 in that trial. No significant difference was found for any organs investigated on both days (two-way ANOVA for "treatment" factor: $N=15-25, d f=$ $1, F=0.66,0.01,0.50$ for testis, seminal vesicle, and accessory gland, respectively, $P>0.42$ each; data not shown).

When $100 \mu \mathrm{g}$ of methoprene was applied on days 2 and 5, no significant difference was found between the dry weights of the testis and seminal vesicle ( $t$ test: $d f=65,78, t<1.70, P>0.05$; Figure 2). Like the day 0 treatment, the dry weight of accessory glands was significantly lower on day 5 when drones were treated on day $2(d f=78$, $t=5.49, P<0.001$; Figure 2), but no significant difference was found when drones were treated on day $5(d f=65, t=0.58, P=0.57$; Figure 2$)$.

\subsection{Experiment 2: distribution in colony}

The proportion of both control and treated drones found on the peripheral frames increased during the observation period (Figure 3b). Drones treated with $100 \mu \mathrm{g}$ of methoprene tended to move to the peripheral frames earlier than other drones. Significant differences were found between the proportion of drones on the peripheral frames between 100- $\mathrm{g}$-treated drones versus $1-\mu g$-treated drones and between $100-\mu g$-treated drones versus controls on days 5 and 6 (chi-square test: day $5-d f=2, \chi^{2}=50.7$, $P<0.001$; day $6-\chi^{2}=20.1, P<0.001$; Tukey's WSD test: $P<0.05$; Figure $3 b)$. The difference disappeared as drones became older $(P>0.05)$. Drones treated with $1 \mu \mathrm{g}$ of methoprene showed the same change as the controls, and there was no statistical difference between them $(P>0.05)$. 
A total of 48 drones disappeared during the observation period. This was probably due to failure to return from an orientation flight because $91 \%$ of the loss occurred after day 6 .

a

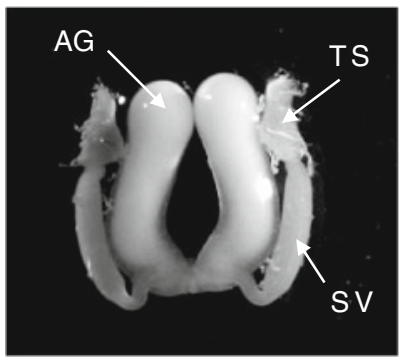

$\underline{\text { Trial } 1}$

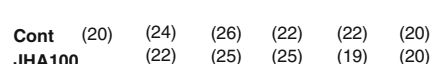

JHA100 (22) (25) (25) (19) (20)
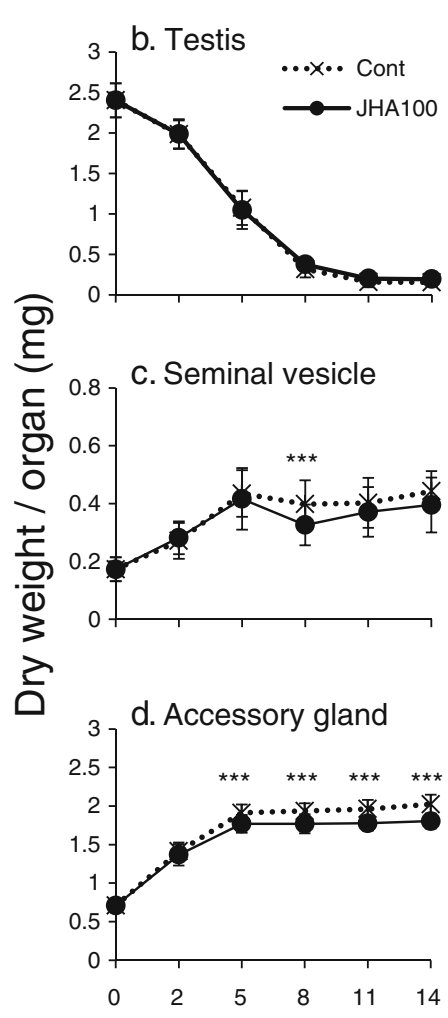

Trial 2

Trial 3

\begin{tabular}{|c|c|c|c|c|c|c|c|c|c|}
\hline (20) & (16) & (19) & (29) & (26) & (26) & Cont & (25) & (20) & (15) \\
\hline JHA10 & (16) & (20) & (31) & (33) & (34) & JHA10 & (20) & (22) & (26) \\
\hline JHA500 & (15) & (21) & (20) & (17) & (9) & JHA100 & (23) & (26) & (13) \\
\hline
\end{tabular}
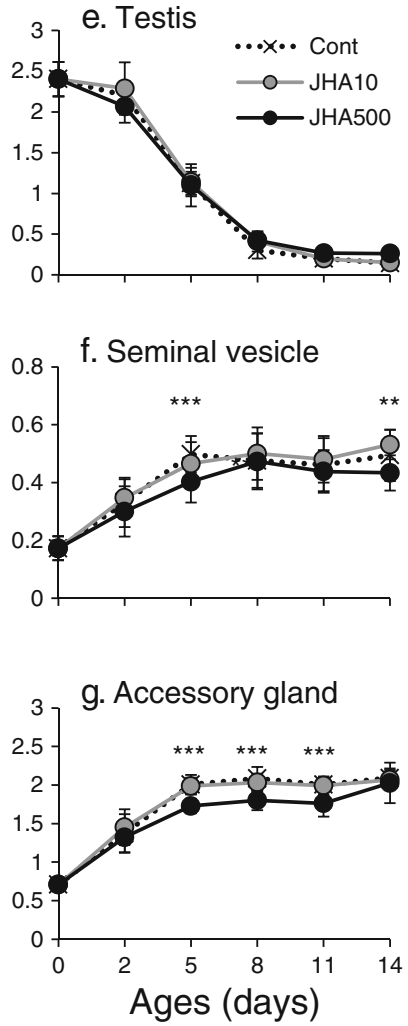
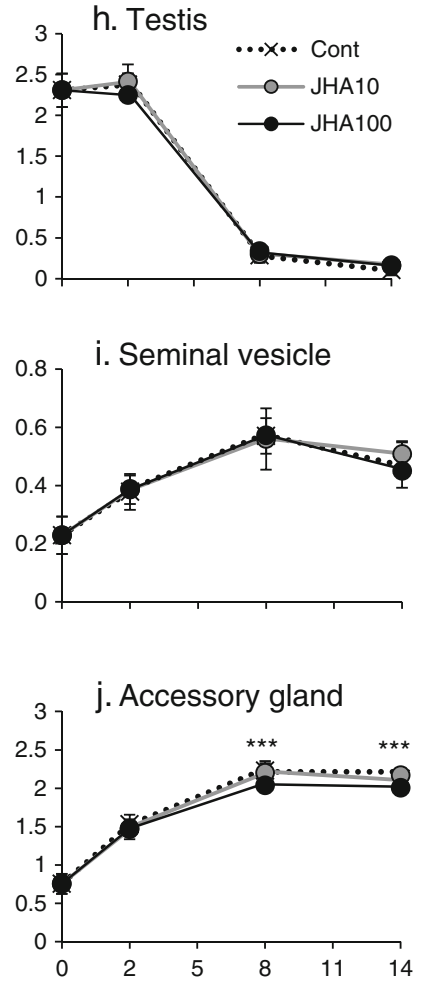

Figure 1. Photograph of male reproductive organs in A. mellifera (a) and changes in dry weight for each organ in methoprene-treated and control drones $(\mathbf{b}-\mathbf{j})$. Treatment was administered on day 0 . TS testis, $S V$ seminal vesicle, $A G$ accessory gland, Cont solvent control. JHA 10, JHA 100, and JHA 500 treatments with 10, 100, and $500 \mu \mathrm{g}$ of methoprene, respectively. ${ }^{* *} P<0.01 ; * * * P<0.001$ (by ANOVA). Error bars indicate SDs. Sample sizes are shown in parentheses. 
Table I. Results of two-way ANOVAs for the effect of methoprene and age on the dry weight of male reproductive organs.

\begin{tabular}{|c|c|c|c|c|c|c|c|c|c|c|c|}
\hline \multirow[t]{3}{*}{ Trial } & \multirow[t]{3}{*}{ Treatment } & \multirow[t]{3}{*}{$N$} & \multicolumn{9}{|c|}{ Significance by two-way ANOVA $^{\mathrm{a}}$} \\
\hline & & & \multicolumn{3}{|l|}{ Testis } & \multicolumn{3}{|c|}{ Seminal vesicle } & \multicolumn{3}{|c|}{ Accessory gland } \\
\hline & & & $\begin{array}{l}\text { (A) } \\
\text { Treatment }\end{array}$ & $\begin{array}{l}\text { (B) } \\
\text { Age }\end{array}$ & $\mathrm{A} \times \mathrm{B}$ & $\begin{array}{l}\text { (A) } \\
\text { Treatment }\end{array}$ & $\begin{array}{l}\text { (B) } \\
\text { Age }\end{array}$ & $\mathrm{A} \times \mathrm{B}$ & $\begin{array}{l}\text { (A) } \\
\text { Treatment }\end{array}$ & $\begin{array}{l}\text { (B) } \\
\text { Age }\end{array}$ & $\mathrm{A} \times \mathrm{B}$ \\
\hline \multirow[t]{2}{*}{1} & Control & $20-26$ & 0.22 & $* * *$ & 0.61 & $* *$ & $* * *$ & 0.15 & $* * *$ & $* * *$ & $* *$ \\
\hline & JHA $100^{\mathrm{b}}$ & $19-25$ & & & & & & & & & \\
\hline \multirow[t]{3}{*}{2} & Control & $16-29$ & & & & & & & & & \\
\hline & JHA10 $0^{\mathrm{b}}$ & $16-34$ & 0.07 & $* * *$ & $* * *$ & $* * *$ & $* * *$ & 0.21 & $* * *$ & $* * *$ & $* *$ \\
\hline & JHA $500^{\mathrm{b}}$ & $9-20$ & & & & & & & & & \\
\hline \multirow[t]{3}{*}{3} & Control & $15-25$ & & & & & & & & & \\
\hline & JHA $10^{\mathrm{b}}$ & $20-26$ & 0.18 & $* * *$ & $* * *$ & 0.50 & $* * *$ & 0.23 & $* * *$ & $* * *$ & $* *$ \\
\hline & JHA $100^{\mathrm{b}}$ & $13-23$ & & & & & & & & & \\
\hline
\end{tabular}

\footnotetext{
${ }^{\text {a }}$ Numerals show $P$ values

${ }^{\mathrm{b}} \mathrm{JHA} 10,100$, and 500 indicate treatments with 10,100 , and $500 \mu \mathrm{g}$ of methoprene, respectively **P $P<0.01 ; * * * P<0.001$
}

\subsection{Experiment 3: mid-gut contents}

More than $60 \%$ of day 2 control drones were scored as grade I. Trial 1 showed that mid-gut solids decreased as drones aged and almost none were found on day 8. As a result, we focused on days 2 and 5 in trial 2.

A significant effect of methoprene appeared in drones on day 2 (Figure $4 b, c$ ) when the amount of solids was smaller in treated drones than in controls. Drones treated with $10 \mu \mathrm{g}$ of methoprene showed a statistically higher grade than controls in trial 1 (Mann-Whitney's $U$ test: $P<0.05)$. A dose-dependent decrease in grade was found in trial 2 (Kruskal-Wallis test, SteelDwass test: $P<0.05)$. There was no significant difference at later ages $(P>0.05)$.

The mid-gut contents of day 2 drones found in the central brood area and in the periphery showed no significant difference with position (chi-square test: $N=60, d f=2, \chi^{2}=1.626$, $P=0.92$; data not shown).

Some mid-guts with solids were dissected under a light microscope to observe the materials closely. Some contained pollen grains (Figure 5a, b) and others contained jelly-like opaque material with a few pollen grains (Figure 5c, d). These materials were both yellowish, but the former was darker. These materials are not distinguished in Figure 4.

\section{DISCUSSION}

\subsection{Role of $\mathrm{JH}$ in physiological maturation}

Drones treated with 1-500 $\mu \mathrm{g}$ of methoprene at emergence or on later days showed no sign of accelerated maturation in the testis, seminal vesicle, and accessory gland. JHA appeared to depress maturation of the seminal vesicle and accessory gland. A significant decrease in weight was observed in all three trials for accessory glands, but was only found in two of the three trials for seminal vesicles when more than $100 \mu \mathrm{g}$ of methoprene was applied (Table I), suggesting that the former organ is more sensitive to methoprene than the latter.

The effect of methoprene on physiological maturation in honeybee males seems opposite to the effect in other insects, where JH stimulates maturation of the accessory gland (Wigglesworth 1936; Loher 1961; Blaine and Dixon 1973; 
a. Day 5 (treated on day 2)

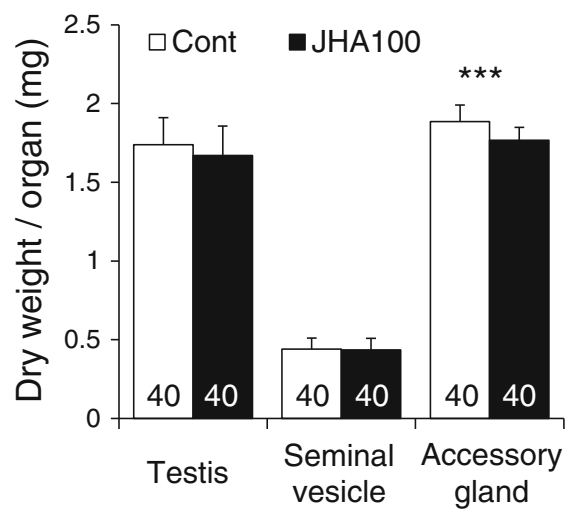

b. Day 9 (treated on day 5)

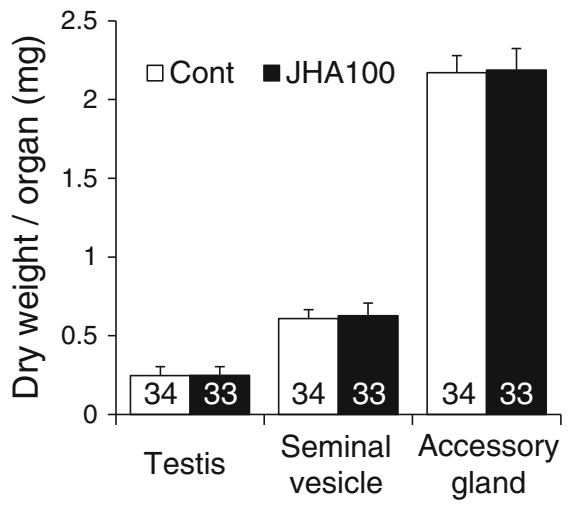

Figure 2. Effects of $100 \mu \mathrm{g}$ of methoprene treatment on day 2 (a) and day 5 (b) on the dry weight of testis, seminal vesicle, and accessory gland in A. mellifera males. Cont solvent control. JHA 100 a treatment with $100 \mu \mathrm{g}$ of methoprene. ${ }^{* * *} P<0.001$ (by $t$ test). Error bars indicate SDs. Sample sizes are shown in bars.

Herman 1975; Herman and Bennett 1975; Ramalingam and Craig 1977; Piulachs et al. 1992). However, it is unlikely that JH functions as an inhibitor of sexual maturation in drones because the $\mathrm{JH}$ production and hemolymph titer increase with maturation of reproductive organs (Tozetto et al. 1995; Giray and Robinson 1996; Harano et al. 2008). The depressed maturation in treated drones may be explained by a disruption of the hormone system due to the abnormal JHA dose or by a side effect of behavioral modifica- tion caused by the methoprene, as described below.

Although the results agree with the view that $\mathrm{JH}$ has no gonadotropic function in honeybee males as well as females, further examination using different methods such allatectomy and spermatozoa counting is needed to draw a firm conclusion.

\subsection{Role in in-colony movement}

Consistent with previous observations by Free (1957) and Ohtani and Fukuda (1977), drones tended to move to the colony periphery as they aged. Drones treated with a high dose of methoprene moved earlier than other drones, suggesting that $\mathrm{JH}$ is involved in the regulation of drone's age-dependent movement. A similar in-colony movement with age is known in workers, which also move from the central brood to the colony periphery and finally leave for foraging (Seeley 1982). This movement basically depends on age and position in the colony and is associated with worker task. Although a physiological mechanism controlling movement is yet to be shown in workers, it might be regulated by $\mathrm{JH}$ because this hormone controls task transition (Jaycox et al. 1974; Jaycox 1976; Robinson 1985, 1987; Sasagawa et al. 1989).

Ohtani and Fukuda (1977) argue that agespecific temperature preference is responsible for in-hive male movement. $\mathrm{JH}$ may induce the movement by changing the temperature preference in males.

\subsection{Role in feeding behavior}

While drones are fed by workers by trophallaxis, they also feed themselves on honey in cells. The frequency of trophallaxis by workers is high during the week after emergence and decreases with age. Drones older than 6 days feed themselves entirely with honey and are rarely fed by workers (Free 1957). Although the food that drones are fed by workers is unclear, they might be fed with larval food (Haydak 1970) because the age of feeding workers is similar to that of nurse bees (Free 1957). Larvae 
a.
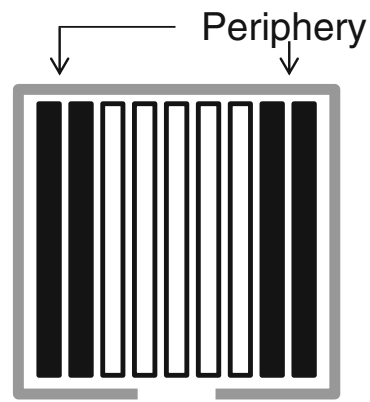

b.

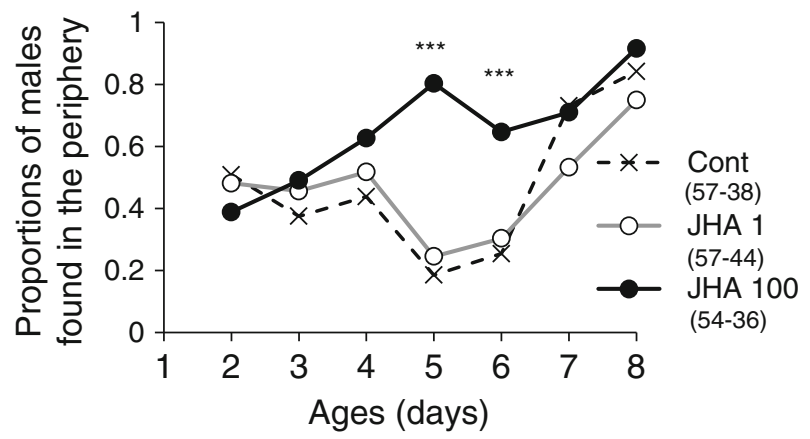

Figure 3. Graphical representation of the arrangement of frames in a hive (a) and effects of methoprene on the distribution of $A$. mellifera males in the hive (b). Black and open rectangles indicate peripheral honey frames and central brood frames, respectively (a). The proportions of drones found on the peripheral frames are shown in (b). Cont solvent control. JHA 1 and JHA 100 treatments with 1 and $100 \mu \mathrm{g}$ of methoprene, respectively. ${ }^{* * * P<0.001}$ (by chi-square test). Maximum and minimum sample sizes are shown in parenthesis (see text).

are fed with a mixture of protein-rich secretions from the hypopharyngeal and mandibular glands for a few days after hatching and then with diluted honey and pollen at later developmental stages (Winston 1987). An opaque jellylike material and pollen grains were observed in the mid-gut of drones. Although the identity of the former material is unknown, the jelly-like material might be a secretion of workers. Perhaps drones use these materials as a protein source for the development of flight muscles and reproductive organs. Mature drones may require honey rather than proteinaceous food for mating flights. Workers also undergo similar changes in food with aging. Young workers consume a considerable amount of pollen, whereas older workers such as foragers feed exclusively on honey (Winston 1987). No endocrinological mechanism underlying the change of food has been revealed for workers. In the mosquito Culex pipiens, a JH-mediated mechanism has been suggested in the transition from nectar to blood meals (Hancock and Foster 1992).

The results of the inspection of mid-gut contents suggest that diet transition is accelerated by $\mathrm{JH}$ in drones. This hormone might affect drone's preference for a particular food. Another possible explanation is that the accelerated diet transition is attributed to an indirect effect of methoprene on in-colony position. Young drones that have moved to the periphery may be fed by workers less frequently because there are fewer young bees or nurse bees in the 
a

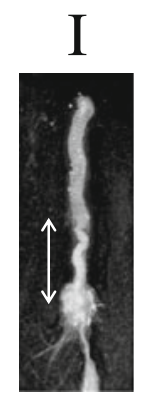

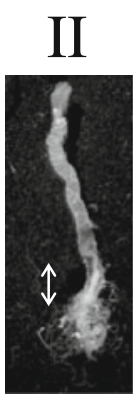

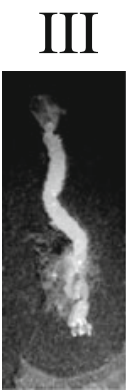

b. Trial 1
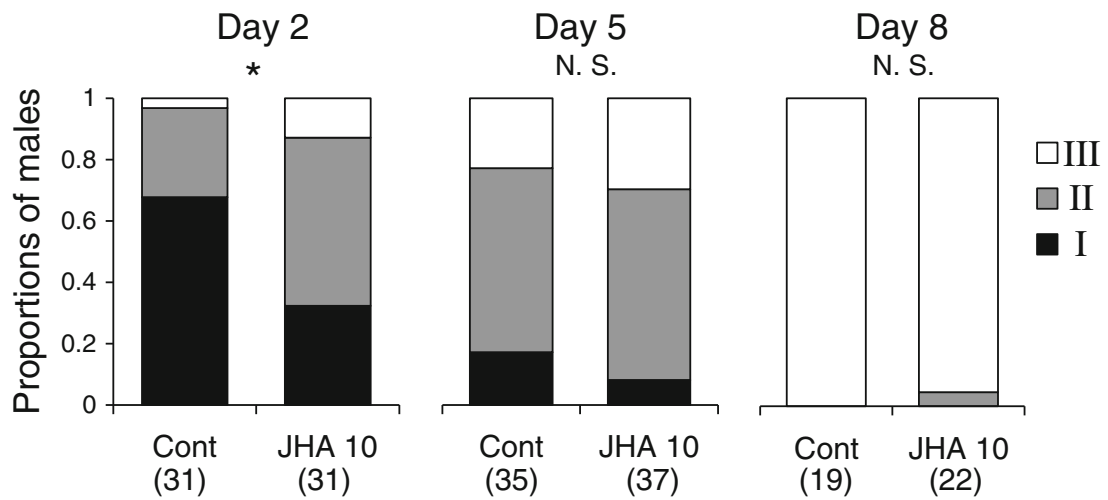

\section{c. Trial 2}
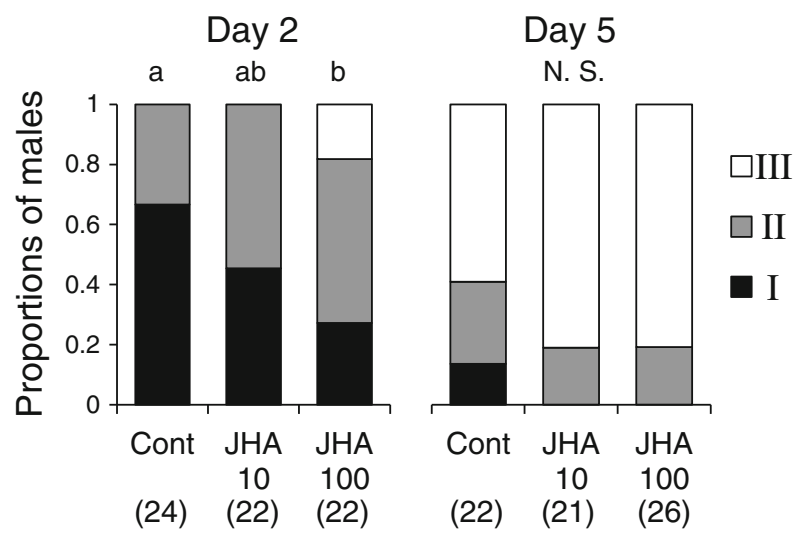

Figure 4. Graphical representation of grades I-III of mid-gut content (a) and the effects of methoprene on midgut content in A. mellifera males (b, c). Arrows indicate the mid-gut portion containing "solid" materials (a). The proportions of drones with each grade are shown for control and methoprene-treated drones in (b) and (c). Cont solvent control. JHA 10 and JHA 100 treatments with 10 and $100 \mu \mathrm{g}$ of methoprene, respectively. $* P<0.05$ (by Mann-Whitney's $U$ test). N.S. non-significant. Different letters indicate a significant difference with Steel-Dwass test at the $5 \%$ significance level (c). Sample sizes are shown in parentheses. 

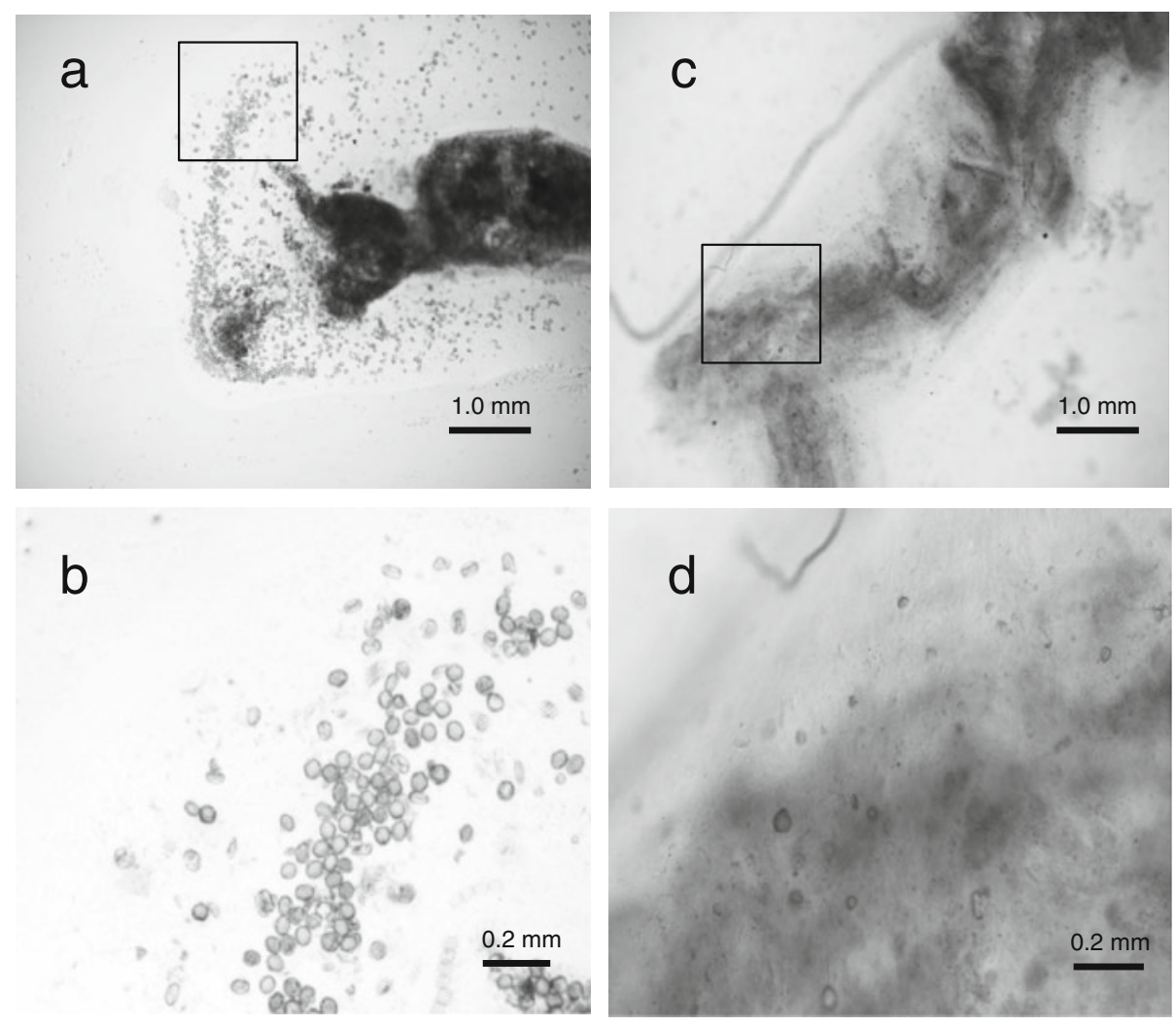

Figure 5. Photographs of mid-gut content. Two types of food were found in the mid-gut: pollen (a, b) and a jelly-like opaque substance (c, d). Areas surrounded by lines in (a) and (c) are magnified in (b) and (d).

periphery compared to the brood area. However, this explanation is unlikely because methoprene affected mid-gut contents before the in-colony movement, and mid-gut contents were not significantly different between drones captured in the central brood area and colony periphery.

Since a high dose of methoprene appeared to cause earlier cessation of intake of proteinaceous diet, the treatment may cause a shortage of protein in drones. Perhaps depressed maturation in the seminal vesicle and accessory gland is the result of poor nutrition in methoprene-treated drones. Normally, drones were fed extensively by workers and increase their total nitrogen content greatly in the first 4 days after emergence (DeGroot 1953). In workers, pollen consumption is an important factor in glandular development during the adult stage (Maurizio 1950).

\subsection{Social evolution and functions of JH}

$\mathrm{JH}$ stimulates various aspects of insect reproduction, especially ovarian development in females (Wyatt and Davey 1996), but there is no evidence for such a gonadotropic function for $\mathrm{JH}$ in both adult queens and workers of honeybees (van Laere 1974; Engels and Ramamurty 1976; Engels 1978; Robinson et al. 1992; Fahrbach et al. 1995). Thus, it seems as if $\mathrm{JH}$ has lost its gonadotropic function during the social evolution of honeybees (Robinson and Vargo 1997; Hartfelder 2000), although it still induces vitellogenin gene expression in the late pupal stages in both female castes (Barchuk et al. 2002). The present study did not find any sign of a gonadotropic effect of $\mathrm{JH}$ in drones. However, $\mathrm{JH}$ appears to 
regulate behavioral development in drones as well as in workers. Giray and Robinson (1996) showed that $\mathrm{JH}$ promotes flight in drones as in workers, suggesting the same endocrinal mechanisms underlying the regulation of flight in both. The present study demonstrated that $\mathrm{JH}$ regulates other behaviors that change with age, suggesting that $\mathrm{JH}$ functions as a pacemaker controlling behavioral development generally in drones - as proposed for workers (Robinson and Vargo 1997) rather than simply activating particular behaviors.

The present study supports the argument that the function of $\mathrm{JH}$ in controlling behavior has not been evolved exclusively for division of worker labor (Giray and Robinson 1996) because the same endocrine mechanism is present in drones without division of labor. Perhaps JH first changed function to regulate behavioral development adaptively to some condition shared between the sexes. The endocrine system might then have been converted to a regulator of sophisticated age polyethism in workers.

\section{ACKNOWLEDGMENTS}

I am grateful to Dr. M. Sasaki of Tamagawa University and Dr. K. Sasaki of Kanazawa Institute of Technology for stimulating discussion. I also thank Mr. S. Hayashi for his apiary assistance. This study is partially supported by a strategic research center establishment program of Tamagawa University (S0901017) granted by the Ministry of Education, Culture, Sport, Science and Technology, Japan.

Effets de l'analogue de l'hormone juvénile sur la maturation physiologique et comportementale des mâles de l'abeille

Apis mellifera / développement du comportement / mâle / hormone juvénile / reproduction / maturation sexuelle

Effekte eines Juvenilhormon-Analogs auf Physiologie und Verhalten im Sexualreifungsprozess von Drohnen der Honigbiene

Verhaltensentwicklung / Drohn / Juvenilhormon / Reproduktion / sexuelle Reifung

\section{REFERENCES}

Akasaka, S., Sasaki, K., Harano, K., Nagao, T. (2010) Dopamine enhances locomotor activity for mating in male honeybees (Apis mellifera L.). J. Insect Physiol. 56, 1160-1166

Barchuk, A.R., Bitondi, M.M.G., Simões, Z.L.P. (2002) Effects of juvenile hormone and ecdysone on the timing of vitellogenin appearance in hemolymph of queen and worker pupae of Apis mellifera. J. Insect Sci. 2, 1-8

Barker, J.F. (1978) Neuroendocrine regulation of oocyte maturation in the imported fire ant Solenopsis invicta. Gen. Comp. Endocrinol. 35, 234-237

Blaine, W.D., Dixon, S.E. (1973) The effect of juvenile hormone on the function of the accessory gland of the adult male cockroach Periplaneta americana (Orthoptera: Blattidae). Can. Entomol. 105, 1275-1280

Bloch, G., Borst, D.W., Huang, Z.-Y., Robinson, G.E., Hefetz, A. (1996) Effects of social conditions on juvenile hormone mediated reproductive development in Bombus terrestris workers. Physiol. Entomol. 21, 257-267

Bloch, G., Borst, D.W., Huang, Z.-Y., Robinson, G.E., Cnaani, J., Hefetz, A. (2000) Juvenile hormone titers, juvenile hormone biosynthesis, ovarian development and social environment in Bombus terrestris. J. Insect Physiol. 46, 47-57

Bohm, M.K. (1972) Effects of environment and juvenile hormone on ovaries of the wasp, Polistes metricus. J. Insect Physiol. 18, 1875-1883

Colonello, N.A., Hartfelder, K. (2003) Protein content and pattern during mucus gland maturation and its ecdysteroid control in honey bee drones. Apidologie 34, 257-267

DeGroot, A. P. (1953) Protein and amino acid requirements of the honeybee (Apis mellifera L.). Physiol. Comparata et Oecolog. 3, 90

Dombroski, T.C.D., Simões, Z.L.P., Bitondi, M.M.G. (2003) Dietary dopamine causes ovary activation in queenless Apis mellifera workers. Apidologie 34, 281-289

Engels, W. (1978) Der Einfluss verschiedener Juvenilhormone und Dosierungen auf den VitellogeninStoffwechsel eierlegender Bienenkoeniginnen (Apis mellifica). Mitt. Dtsch Ges. Allg. Angew. Entomol. 1, 308-312

Engels, W., Ramamurty, P.S. (1976) Initiation of oogenesis in allatectomised virgin honey bee queens by carbon dioxide treatment. J. Insect Physiol. 22, $1427-1432$

Evans, P.D. (1980) Biogenic amines in the insect nervous system. Adv. Insect Physiol. 15, 317-474

Fahrbach, S.E., Giray, T., Robinson, G.E. (1995) Volume changes in the mushroom bodies of adult honey bee queens. Neurobiol. Learn. Mem. 63, 181-191

Free, J.B. (1957) The food of adult drone honeybees (Apis mellifera). Anim. Behav. 5, 7-11 
Giray, T., Robinson, G.E. (1996) Common endocrine and genetic mechanisms of behavioral development in male and worker honey bees and the evolution of division of labor. Proc. Natl. Acad. Sci. U. S. A. 93, 11718-11722

Hancock, R.G., Foster, W.A. (1992) Juvenile hormonemediated host-seeking behavior in mosquitoes: effects of energy-reserve status. In: Mauchamp, B., Couillaud, F., Baehr, J.C. (eds.) Insect juvenile hormone research-fundamental and applied approaches, pp. 111-118. INRA, Paris

Harano, K., Sasaki, K. (2013) Sexual maturation, mating strategies and neuroendocrinology in social insects. In: Nakamura, M., Ito, T. (eds.) Human and animal mating: strategies, gender differences and environmental influences. Nova Science Publishers, Hauppauge, NY

Harano, K., Sasaki, K., Nagao, T., Sasaki, M. (2008) Influence of age and juvenile hormone on brain dopamine level in male honeybee (Apis mellifera): association with reproductive maturation. J. Insect Physiol. 54, 848-853

Harris, J.W., Woodring, J. (1995) Elevated brain dopamine levels associated with ovary development in queenless worker honey bees (Apis mellifera L.). Comp. Biochem. Physiol. 111C, 271-279

Hartfelder, K. (2000) Insect juvenile hormone: from "status quo" to high society. Braz. J. Med. Biol. Res. 33, $157-177$

Haydak, M.H. (1970) Honey bee nutrition. Annu. Rev. Entomol. 15, 143-156

Herman, W.S. (1975) Juvenile hormone stimulation of tubular and accessory glands in male Monarch butterflies. Comp. Biochem. Physiol. A 51, 507-510

Herman, W.S., Bennett, D.C. (1975) Regulation of oogenesis, female specific protein production, and male and female reproductive gland development by juvenile hormone in the butterfly, Nymphalis antiopa. J. Comp. Physiol. 99, 331-338

Jassim, O., Huang, Z.-Y., Robinson, G.E. (2000) Juvenile hormone profiles of worker honey bees, Apis mellifera, during normal and accelerated behavioural development. J. Insect Physiol. 46, 243-249

Jaycox, E.R. (1976) Behavioral changes in worker honey bees (Apis mellifera L.) after injection with synthetic juvenile hormone (Hymenoptera: Apidae). J. Kansas Entomol. Soc. 49, 165-170

Jaycox, E.R. (1961) The effects of various foods and temperatures on sexual maturity of the drone honey bee (Apis mellifera). Ann. Entomol. Soc. Am. 54, 519-523

Jaycox, E.R., Skowronek, W., Gwynn, G. (1974) Behavioral changes in worker honey bees (Apis mellifera) induced by injections of a juvenile hormone mimic. Ann. Entomol. Soc. Am. 67, 529-534

Kearney, G.P., Toom, P.M., Blomquist, G.J. (1977) Induction of de-alation in virgin female Solenopsis invicta with juvenile hormones. Ann. Entomol. Soc. Am. 70, 699-701 van Laere, O. (1974) Physiology of the honeybee corpora allata 3. A new method for allatectomy of queens. J. Apic. Res. 13, 15-18

Loher, W. (1961) The chemical acceleration of the maturation process and its hormonal control in the male of the desert locust. Proc. R. Soc. Lond. B 153, 380-397

Maurizio, A. (1950) The influence of pollen feeding and brood rearing on the length of life and physiological condition of the honeybee. Bee World 31, 9-12

Mezawa, R., Akasaka, S., Nagao, T., Sasaki, K. (2013) Neuroendocrine mechanisms underlying regulation of mating flight behaviors in male honey bees (Apis mellifera L.). Gen. Comp. Endocrinol. 186, 108-115

Ohtani, T., Fukuda, H. (1977) Factors governing the spatial distribution of adult drone honeybees in the hive. J. Apic. Res. 16, 14-26

Piulachs, M.D., Maestro, J.L., Bellés, X. (1992) Juvenile hormone production and accessory reproductive gland development during sexual maturation of male Blattella germanica (L.) (Dictyoptera, Blattellidae). Comp. Biochem. Physiol. A 102, 477-480

Ramalingam, S., Craig, G.B. (1977) The effects of a JH mimic and cauterization of the corpus allatum complex on the male accessory glands of Aedes aegypti (Diptera: Culicidae). Can. Entomol. 109, 897-906

Robinson, G.E. (1985) Effects of a juvenile hormone analogue on honey bee foraging behavior and alarm pheromone production. J. Insect Physiol. 31, 277-282

Robinson, G.E. (1987) Regulation of honey bee age polyethism by juvenile hormone. Behav. Ecol. Sociobiol. 20, 329-338

Robinson, G.E., Vargo, E.L. (1997) Juvenile hormone in adult eusocial hymenoptera: gonadotropin and behavioral pacemaker. Arch. Insect Biochem. Physiol. 35, 559-583

Robinson, G.E., Strambi, C., Strambi, A., Feldlaufer, M.F. (1991) Comparison of juvenile hormone and ecdysteroid haemolymph titres in adult worker and queen honey bees (Apis mellifera). J. Insect Physiol. 37, 929-935

Robinson, G.E., Strambi, C., Strambi, A., Huang, Z.-Y. (1992) Reproduction in worker honey bees is associated with low juvenile hormone titers and rates of biosynthesis. Gen. Comp. Endocrinol. 87, 471-480

Röseler, P.F., Röseler, I., Strambi, A. (1980) The activity of corpora allata in dominant and subordinated females of the wasp Polistes gallicus. Insectes Soc. 27, 97-107

Rueppell, O., Page, R.E., Fondrk, M.K. (2006) Male behavioural maturation rate responds to selection on pollen hoarding in honeybees. Anim. Behav. 71, 227-234

Ruttner, F. (1966) The life and flight activity of drones. Bee World 47, 93-100

Sasagawa, H., Sasaki, M., Okada, I. (1989) Hormonal control of the division of labor in adult honeybees (Apis mellifera L.). I. Effect of methoprene on corpora allata and hypopharyngeal gland, and its alphaglucosidase activity. Appl. Entomol. Zool. 24, 66-77 
Sasaki, K., Nagao, T. (2001) Distribution and levels of dopamine and its metabolites in brains of reproductive workers in honeybees. J. Insect Physiol. 47, 1205-1216

Sasaki, K., Harano, K. (2010) Multiple regulatory roles of dopamine in behavior and reproduction of social insects. Trends Entomol. 6, 1-13

Seeley, T.D. (1982) Adaptive significance of the age polyethism schedule in honeybee colonies. Behav. Ecol. Sociobiol. 11, 287-293

Snodgrass, R.E. (1956) Anatomy of the honey bee. Cornel University Press, Ithaca

Tozetto, S.O., Rachinsky, A., Engels, W. (1995) Reactivation of juvenile hormone synthesis in adult drones of the honey bee, Apis mellifera carnica. Experientia 51, 945-946
Tozetto, S.O., Rachinsky, A., Engels, W. (1997) Juvenile hormone promotes flight activity in drones (Apis mellifera carnica). Apidologie 28, 77-84

Vargo, E.L., Laurel, M. (1994) Studies on the mode of action of a queen primer pheromone of the fire ant Solenopsis invicta. J. Insect Physiol. 40, 601-610

Wigglesworth, V.B. (1936) The function of the corpus allatum in the growth and reproduction of Rhodnius prolixus (Hemiptera). Quart. J. Microscop. Sci. 79, 91-121

Winston, M.L. (1987) The biology of the honeybee. Harvard University Press, Cambridge

Wyatt, G.R., Davey, K.G. (1996) Cellular and molecular actions of juvenile hormone. II. Roles of juvenile hormone in adult insects. Adv. Insect Physiol. 26, 1156 